USARSKI, Frank. O budismo e as outras: encontros e desencontros entre as grandes religiões mundiais. Aparecida-SP: Editora Idéias e Letras, 2009, 304pp.

\title{
A IDENTIDADE BUDISTA EM DIÁlOGO COM A DIVERSIDADE RELIGIOSA
}

Daniel Alves

O estudo sobre a comunicação entre as grandes religiões universais guarda uma história associada a contextos políticos, econômicos, e culturais. Esses diálogos nem sempre são amistosos, sendo por vezes repletos de lacunas ou mal-entendidos, dado que cada parte enquadra a conversação a partir de seu próprio horizonte de sentido, que é ainda refratado pela posição dos interlocutores no contexto mais amplo do encontro de civilizações. Quando existem esses diálogos, fundamentam-se em ideias cosmológicas e soteriológicas das religiões, desenvolvidas por especialistas em produção simbólica religiosa como missionários, líderes, teólogos ou filósofos. O livro de Frank Usarski mapeia as relações entre o Budismo e outras religiões universais, a saber: o Hinduísmo, o Cristianismo, o Judaísmo e o Islamismo. Dado que a maior parte do livro centra-se no diálogo do Budismo com as duas primeiras, esta resenha centrar-se-á nestas, para ao final descrever sucintamente a relação com as duas últimas.

O livro é de conteúdo eminentemente informativo, utilizando algumas ferramentas teóricas para dar o enquadramento analítico necessário ao objeto. Apesar das simpatias teóricas reveladas aqui e ali pela teoria dos sistemas de Luhmann, não há investimento em discussões teoréticas. Esse fato é compensado por uma introdução, no primeiro capítulo, a conceitos centrais do Budismo sabidamente complexos, que demandam atenção e uma exposição consistente, pois implicam no entendimento do restante do livro. As citações acadêmicas, em sua maior parte, indicam a leitura de literatura estrangeira ligada à área específica de estudos sobre Budismo, muito mais forte nos Estados Unidos e Europa que na América Latina.

No primeiro capítulo, o autor faz uma síntese de conceitos budistas, na busca de encontrar um "mínimo denominador comum" entre as tradições que emergiram a partir de Siddharta Gautama. Nesse mínimo, temos uma síntese de conceitos como lei do carma, skandhas, gênese condicionada, annata, samsara, nirvana, as quatro nobres verdades, refúgio e o nobre caminho óctuplo, sendo que há referências indiretas a um conjunto de ensinamentos budistas que identificam como os seres surgem em samsara, conhecidos e ilustrados como os doze elos da originação interdependente. A todo o 
momento, porém, a compreensão desse mínimo é reportada para dentro da diversidade interna das grandes tradições (yanas), já apontando algo das transformações históricas através das quais o budismo dialogou com as culturas, escudando de antemão o leitor de uma compreensão essencialista do budismo. É salutar, desta maneira, a complementaridade feita entre a perspectiva vertical (que separa o budismo "popular" dos leigos do rigor e da escolástica dos monges, característica dos países asiáticos) e a perspectiva horizontal das tradições (na seqüência tradicional de apresentação, Theravada, Mahayana, Vajrayana e Budismo Ocidental). Como é comum nas apresentações históricas do Budismo, dá-se ênfase na perspectiva horizontal e, dentre os veículos, o autor detém-se sobremaneira no desenvolvimento filosófico proporcionado pelo Budismo Mahayana há vinte séculos, em face da postura tradicional de controle rígido de conduta na tradição antiga (Theravada). Esse desenvolvimento filosófico teria dado ao Budismo Mahayana a capacidade de se adaptar mais facilmente que a tradição antiga. No que tange ao livro em questão, o enquadramento mais filosófico proporcionado por Mahayana influencia a apresentação dos conceitos trazidos pelo autor ao início, embora esses conceitos de fato possam ser generalizados para todas as tradições. Chama a atenção, ainda, a exposição do Budismo Ocidental como um "quarto veículo", entendimento que parece ter se tornado comum nos estudos especializados tanto entre especialistas do campo científico quanto dos professores budistas.

Para um leitor pouco familiarizado com os conceitos, o primeiro capítulo pode ser realmente desafiador. Aos interessados pela história dos encontros entre o Budismo e as outras religiões, o segundo capítulo é uma leitura interessante. Nele, busca-se uma compreensão histórica da relação do Budismo com as outras religiões supracitadas. O quadro geral das relações é mais denso nas relações com o Hinduísmo e o Cristianismo. Criticando o sistema de castas hindu e colhendo adeptos entre todas elas (e, portanto, indo de encontro ao monopólio dos Brâmanes no que tange ao ensino a outras castas), os ensinamentos de Siddharta Gautama não só desenvolveram uma psicologia e soteriologia próprias, mas também formas de relacionar-se com o Hinduísmo que permitiram uma adaptação dos conversos às comunidades budistas primeiras. Durante os primeiros séculos de convivência, os governantes hindus tinham uma relação com o Budismo que ia da tolerância à perseguição. Contudo, mesmo quando houve enfrentamento direto, ele nunca foi sistemático. A reação negativa ao Budismo parece ter se concentrado no plano das idéias. Assim, a solução hinduísta para as divergências internas geradas pelo budismo foi a inclusão de Buda como uma emanação de Visnu e reformador do Hinduísmo. Saltando alguns séculos de história, o autor ainda discorre sobre conflitos por locais sagrados e sobre a adoção dos ensinamentos budistas, no século passado, por parte de dalits (Intocáveis) como suporte ao confronto com a segregação de casta. Em síntese, o autor revela a história antiga e recente de duas religiões tolerantes, que fundamentam num quadro hierarquizado a prevalência dos princípios de uma com a adoção dos princípios da outra. 
Ao longo dos dois últimos milênios, houve vários encontros entre o Budismo e o Cristianismo, sendo que os mais desenvolvidos no livro reportam-se a lugares específicos, como Índia, China, Japão e Sri Lanka. Destacam-se as conjunturas políticas e sociais para a introdução do cristianismo em cada circunstância, num esforço compreensivo sobre fatores endógenos e exógenos a cada sistema. A divisão por país, apesar de apresentada de forma talvez demasiado sistemática, tem o mérito de contrapor-se a certa tendência orientalista que dilui todas essas regiões genericamente perdendo de vista que, por exemplo, o Cristianismo teve reações distintas de introdução na China e no Japão. Em ambos o Cristianismo teve uma aceitação relativa no século XVI, porém na China a dificuldade ergueu-se por conflitos com o sistema local baseado no Confucionismo (religião de Estado) e no Budismo. No Japão, o Cristianismo encontrou inicialmente seu lugar dentro das disputas entre chefes feudais locais, sendo que alguns deles no século XVI deram suporte às comunidades cristãs de japoneses convertidos. A partir do século XVII, no início da Era Tokugawa, o Cristianismo passou a ser sistematicamente perseguido no Japão, enquanto que na China o aumento das tensões sucessivas com os sistemas de conviç̧ão religiosa endógenos (Confucionismo e Budismo) aumentou sobremaneira o número de cristãos chineses nesse mesmo período. $\mathrm{O}$ crescimento do catolicismo chinês foi estancado no início do século XVIII, com a proibição, por parte do Vaticano, de posturas missionárias de acomodação com as culturas locais, associado com o crescimento de tensões da ordem política internacional. Situação inusitada seria a do contato entre Budismo Theravada e Cristianismo no Sri Lanka, país muito influenciado pelo protestantismo holandês no qual o Budismo foi quase erradicado no século XIX, quando foi recuperado em seu status num movimento modernizante do budismo local que contou com o apoio de dois recém-conversos ocidentais, os fundadores da Sociedade Teosófica Helena Blavatsky e Henry Olcott.

O terceiro capítulo apresenta as estratégias retóricas a partir das quais o budismo relacionou-se historicamente com as grandes religiões mundiais. $\mathrm{O}$ autor abre a reflexão distinguindo as posturas inclusivista, pluralista e exclusivista de comunicação entre religiões, colocando tais enquadramentos como tipos ideais e enraizando-as dentro do cânone budista. A postura inclusivista, no Budismo, pressupõe tacitamente a superioridade do dharma em relação às outras religiões, incorporando-as ou valorizando-as sempre dentro de uma linha de evolução na qual o Budismo está ao fim. A postura pluralista pode ser encontrada na ênfase recente do diálogo interreligioso, na valorização do "outro" dentro de sua especificidade. Por último, podemos descobrir no livro que o budismo também pode apresentar-se como exclusivista, desautorizando ou menosprezando enfaticamente outras perspectivas, e que essa postura também pode ser apoiada em trechos da mensagem do Buda. Pela análise retórica e pela classificação empregada, esse capítulo salta aos olhos de quem espera um patamar de análise que se estenda para além da especificidade do Budismo. Voltaremos a isso no final. 
Por fim, Usarski apresenta pontos de discordância fundamentais entre líderes e pensadores budistas e as grandes religiões, baseado nas convicções apresentadas no primeiro capítulo, na história relatada no segundo e nas posturas descritas do terceiro. Na relação com todas elas, os Budistas criticam o teísmo, seja o politeísmo hindu ou o Deus onisciente, onipotente e onipresente das tradições judaica, cristã e muçulmana. Quanto ao hinduísmo, o autor aponta críticas budistas em larga escala ao sistema de castas, à superioridade dos brâmanes e aos sacrifícios de animais, fazendo lembrar o esforço de diferenciação que o Budismo historicamente fez (e faz até hoje) para se dissociar do sistema de crenças que lhe deu origem. O Cristianismo parece aos líderes budistas um sistema mais convergente que o Hindu, a despeito da crítica às pretensões de verdade e de divindade atribuídas à palavra e a pessoa de Jesus Cristo. As convergências estariam no engajamento ético no mundo e mesmo no conceito de Deus. Quanto ao último, o autor recupera a história do contato entre pensadores cristãos ocidentais e budistas japoneses (que resultou, durante o século XX, da chamada Escola de Kyoto) mostrando que seria possível uma leitura do teísmo monoteísta cristão em termos do Budismo Mahayana.

As páginas que diretamente tratam do diálogo com o Judaísmo e o Islamismo ocupam menos de dez por cento do livro. Dado que o judaísmo é uma religião de nascimento, todo o contato histórico entre Judaísmo e Budismo ocorreu por correntes migratórias ou por motivações comerciais. Apesar disso, dois acontecimentos recentes parecem interessantes para repensar essa relação em termos convergentes. Um desses acontecimentos foi o surgimento, no âmbito do movimento beat americano, de judeus convertidos ao Zen como Allen Ginsberg, primeiro protagonista de uma tendência atual de dupla filiação religiosa conhecida nos EUA como $J u B u$, fundamentada principalmente em aproximações místicas entre o Budismo Zen e a Cabala. O outro ponto de convergência estaria sendo fomentado em encontros estimulados pelo Dalai Lama para troca de experiências na diáspora por parte de judeus e tibetanos. A relação com os muçulmanos, por outro lado, é descrita justamente pelo autor como "ambígua". Os primeiros séculos de avanço do Islã sobre o Extremo Oriente deixavam aos budistas duas alternativas: ou serem incorporados como dhimmis ("legalmente protegidos" por terem uma comunidade religiosa reconhecida por "possuírem um livro") ou sofrerem as piores conseqüências da jihad, com a conversão forçada em massa e destruição de centros importantes de culto e estudo. Atualmente, a dificuldade do diálogo entre as duas religiões decorre da dispersão de lideranças muçulmanas. Atentados recentes de grupos extremistas têm estimulado a iniciativa de diálogo de líderes budistas em relação ao Islamismo, assim como o interesse pela mística Sufi.

Portanto, trata-se de um livro relativamente curto e de considerável densidade intelectual, feito por um grande especialista na área em atuação no Brasil. Um livro que poderia ser visto como um projeto: por que não realizar empreitadas semelhantes a partir de outras religiões, ou em segmentos internos do Cristianismo, como o Pentecostal? Apesar da vocação exclusivista da doutrina da Guerra Espiritual, uma 
pesquisa entre líderes provavelmente iria revelar nuanças, como, por exemplo, aproximações intelectuais exercícios rituais de ecumenismo cristão de cunho não necessariamente tolerante com "as outras" não-cristãs. Obviamente, a qualidade do diálogo proporciona a densidade do material, e não surpreende que o livro de Usarski tenha como foco o Budismo, religião de vocação para o inclusivismo e o pluralismo desde seus primórdios. Por isso, entendemos que seria um desafio transpor para outras religiões e contextos o exercício intelectualmente instigante e prazeroso que Frank Usarski, através desta leitura, nos proporciona.

Daniel Alves (danalves1978@yahoo.com.br)

Doutorando em Antropologia Social (Pós-Graduação em Antropologia Social PPGAS/UFRGS). Tem experiência na área de Antropologia, com ênfase em Antropologia da Religião, atuando principalmente nos seguintes temas: religiosidade popular, aparições de nossa senhora, budismo no Brasil, neopentecostalismo, transnacionalização. 